\title{
The Relevance of Social Intelligence for Effective Optimization of Retirement and Successful Ageing
}

\author{
Tanushree Sanwal $^{1}$ (D) Puja Sareen ${ }^{2}$
}

Accepted: 22 October 2021 / Published online: 2 November 2021

(c) The Author(s), under exclusive licence to Springer Science+Business Media, LLC, part of Springer Nature 2021

\begin{abstract}
Retirement is a psycho social process. It refers to the phase of life when a person leaves his job and withdraws from active working life. Proper optimization of retirement is only possible when a person has pre planned his life with proper finances and saving or the government is providing him with a lot of social security benefits. However, such conditions rarely occur as a person is preoccupied in his pre retirement phases. But proper optimization of retirement can also take place when a person has high social intelligence which affects physical and mental health. Hence, this paper is an endeavor to look into the relevance of social intelligence which helps the people in their retirement process in the people. Thus, a survey was done to find the level of Social Intelligence in the people who are ageing and are going to be retired soon. Around 252 people between 55 to 70 years were studied from Delhi and NCR. The result indicated that middle aged and just retired people had high social intelligence as compared to older adults and the former were also able to optimize their retirement effectively for successful ageing. The older adults were not able to cope up with the various issues of retirement due to low social intelligence. Hence, further studies can be carried out to design proper training for enhancement of social intelligence in aged people for their effective optimization of retirement.
\end{abstract}

Keywords Socialintelligence $\cdot$ Retirement $\cdot$ Optimization · Middle aged $\cdot$ Just retired $\cdot$ Older adults

Tanushree Sanwal

tanushreesanwal12@gmail.com

Puja Sareen

psareen@amity.edu

1 Research Scholar, ABS, Amity University, Noida, India

2 Associate Professor, ABS, Amity University, Noida, India 


\section{Purpose of the Study}

Ageing is a process which is universal and continuous. It starts from conception and end with death. The process of ageing cannot be reversed. Ageing is generally accompanied by many issues which are social and psychological in nature. Ageing especially during the time of retirement is crucial. The process of retirement is influenced by many opportunities as well as constraints (Mutran et al., 1997). During the transition stage of retirement, a person's productive contribution decline and he or she becomes economically dependent on others. During this stage the people not only have financial issues but also face lot of health issues. They have lack of proper facilities and scarce resources which increases their dependency. Many people during this transition phase have lot of problem of social exclusion as they cannot take part in any social or community activities due to their financial and psychological issues. Moreover, many people during this stage of transition are all alone as their children have migrated due to work roles and pressure. Caregivers are also rarely available and they face the issue of trust. Further to magnify the problems these growing older adults not only face financial and psychological issues but also has various health issues giving rise to immobility. Abuse and maltreatment are also increasing day by day as their abandonment by near ones is taking place. Many have to take the respite of old age home unwillingly, post retirement.

Hence, in the present scenario of pandemic today, the current study aims to determine the social intelligence of people in their transition phases of retirement. Social intelligence is a prerequisite for good health and successful ageing. Thus, study aims to see if the people in their transition phases of retirement have the social intelligence to deal effectively and tactfully with the society and the environment. Further this study was also done to see the relevance of social intelligence for effective optimization of retirement and successful ageing.

\section{Objectives of the Study}

Thus, the objective of the study is to:

- To study the concept and parameters of social intelligence.

- To study the impact of social intelligence on people in their transition phases of retirement.

- To study the relevance of social intelligence for effective optimization of retirement and successful ageing. 


\section{Introduction}

Process of ageing is multidimensional and includes physical, social and psychological change. Ageing starts with conception and end with death. Old age is the last phase of humans universally. An aged person faces lot of physical as well as psychological problems. During the time of Covid 19, many aged persons lost their lives or lost their near and dear ones. Their problem related to health increased enormously due to low immunity and stress. Physical and mental well being is sometimes rare for an older adult especially during the time of pandemic. To boost their wellbeing aged people has to get involved socially and follow a health regime as the condition of older adults in developing countries like India is very detrimental. They have to face lots of challenges related to their health, finance and family dynamics (Chand, 2018).

Human life span is generally categorized into five stages: Infant stage, childhood stage, adolescence, adulthood and old age. Havighurst (1972) and Hurlock (1980) subdivided the life span into various stages and named them as progressive stages and divided it into 8 stages. Havighrust called them as developmental task and Hurlock used the term 'Periods' or stages. Different terms have also been used for different age groups after 60 years. These are Young old for 60 to 69, OldOld for 70 to 79, Oldest-Old for 80 and above. (Garfein \& Herzog, 1995). The term "young-old" categorizes people who are just retired and are active. Few are also productive and continue to earn as entrepreneurs or consultants. These people sometimes break the stereotype about the normal behavior of elders. This is generally due to the advance medical and health care facilities available.

However, considering the socio- economic situation in India, age 60 years seems an appropriate cutoff, for retired, while it is 65 years in many other countries. Hence, in India, old age begins at 60 years. The Census of India has also marked the age of 60 years as retirement age for the older adults in job sector. Many people in India start preparing themselves for the various financial, social and economic issues that may arise from retirement. Mentally and physically, they try to keep themselves fit, as much possible for any kind of problem.

Retirement is generally a long process in which people first foresee and then adapt to his new circumstances (Reitzes et al., 1996). Retirement experience and its conditions depend on many social and cultural factors. Factors like money, health, status in society, education and occupation influences the process of retirement (Kim et al., 2001). Proper optimization of retirement is possible only when a person is financially secured and enjoys physical and mental well being. Many findings have also revealed that income and health are strongly associated with satisfaction, morale and well being of a person during pre and post retirement (Richardson \& Kilty, 1991).

Atchley (1976) has said that the transition to retirement enclose generally five stages: 1) Honeymoon- In this stage a just retired person is overjoyed as he enjoys freedom from job stress. 2) Disenchantment-This stage is reached after 4-5 years of retirement where a person faces the hardship and financial constraints due to retirement. 3) Reorientation- It is a stage where a person understands the various social and economic constraints of retirement. 4) Stability-In the fourth stage a person 
finally accommodates and adjusts to all the constraints due to retirement. They start focusing on structured activities. 5) Termination- It is ultimately the last stage where the older adult is dependent on others due to severe illness or disability.

India has still not yet attained the levels of a developed country nor achieved the demographic structure typical of a developed country. The problems of children, youth and women, their nutrition, health, education have been in the forefront. The needs of the aged especially during their retirement ages are not taken into consideration and are neither met by the Governmental and Non-Government sectors.

Today, India is undergoing demographic transition with expectancy of life on the increase and decline in the birth rate. Various social changes are taking place. These changes and problems have only enhanced and aggravated during the pandemic. Financial constraints have increased due to loss of job or early retirement of middle-aged people. This has further affected the status of the retired in family and community. At present, a retired person is considered as an emerging problem and efforts are made to collect qualitative and quantitative data on problems of the aged who don't have any income source. Retirement is now a global phenomenon. The condition of the retired person in our country is currently characterized by severe social and psychological issues and this is further transmitted to succeeding generations (Papaioannou et al., 2020). Scarcity of resources and finance is what the older adults is facing today. Relatives who have played a supporting role in aiding these aged retired people are themselves in severe difficulties due to the current pandemic situation. Maltreatment, social exclusion and abuse of the same are increasing day by day. Health issues are not in a par with older adults as well as middle aged retired person due to the novel corona virus. Further Caregiver's due to their engagement with other patients of covid 19 are facing difficulty and stress in rehabilitating such older adults. Thus, abandonment of older adults and middle aged retired by their near and dear ones are taking place.

In this scenario of today, the people who are going to be retired requires intelligence for a good living and to cope with the issues and problems of aging. They need social intelligence to live a stress-free life and deal with their environment tactfully and smartly. Further proper optimization of retirement can only take place when a person has good physical and mental health which in turn can also be achieved through enhanced social participation and intelligence (Picchio \& Ours, 2020; Santini et al., 2020); Xie et al., 2021).

\section{Social Intelligence}

Intelligence is a global capacity of individuals which is generally inherited, however physical and cultural environment also affects one's intelligence. When we think rationally and act according to the purpose or properly deal with a situation, we are said to be Intelligent (Wechsler, 1944). However, Kihlstrom and Cantor (2000) said that this kind of intelligence is social intelligence where we apply our fund of knowledge to social world. Further, when we have the ability to deal wisely with human relations and get along well with others, we have high social intelligence. 
Researchers have presented the widest definition of social intelligence as the people's capability to get along with others, social technique or case in society and having knowledge of social matters of a group, as well as insight into the momentary moods or underlying character traits of strangers.

O'Sullivan (1965), demarcated social intelligence as the skill to evaluate and understand a person and their emotions, outlook, intentions, motives and ideas. These psychological predispositions generally affect one's social behavior. Researchers, also said that when we win cooperation of others and get along well with them, we are showing traits of social intelligence. To sum up we can say social intelligence is a trait which is affected by various ecological variables (Thakur et al., 2013; InsaCabrera et al., 2012). Social Intelligence can also be said as the traditional wisdom we possess or the modern-day smartness required to deal various situations. If a person has social intelligence he or she can also deal effectively with social myths and prejudices. We can say that this kind of intelligence is a social trail which enhances our generosity and sensitivity. We start to have more cooperation, confidence and an enlightened act of vision.

A socially intelligent person has patience, cooperativeness and confidence. He or she has high sensitivity and can understand their social environment. Further he or she uses his or her tact's, humor and memory in a social situation. (Chadha \& Ganesan, 1986). Social competence plays a major role in a middle-aged person who is going to be retired (Sneegas, 1986). Social Intelligence plays an important role in a life of an older adults and helps in successful ageing (Soleimani et al., 2020). A person must have social intelligence for physical and psychological health as researchers has suggested that theory of mind and happiness play important roles in explaining social intelligence (Yeh, 2013; Bukaiei, 2016).

\section{Literature Review}

Our capacity to act in a purposeful manner, think rationally and deal effectively is called Intelligence. Few studies have shown the relationship between age and intelligence (Green, 1969). According to Boone et al. (1993), women had high intelligence and older adults above 70 years had low, while subjects with high education also scored high in intelligence. Further, Pamuk (2020), had said that many beliefs related to memory and intelligence gets change in later life. However, Stuart-Hamilton et al. (2006), conducted research on older adults of age 60-84 years and found that there was no significant relationship between age, knowledge, level of intelligence and paranormal thinking.

Literature also reveals a strong connection between emotional and social intelligence. They are considered same variable which are interlinked (Boyatzis et al., 2015; Crowne, 2009). Studies reveal that emotional intelligence increases with age slightly (Kircaburun et al., 2020). However, many elements of emotional intelligence do not increase with age. These competencies require special training for enhancement (Bonesso et al., 2020). Various ESI models are used to understand personal abilities and social skills of a person (Khilmiyah \& Wiyono, 2021). These social skills or social intelligence also enhances commitment and learning in an individual 
specially in job sectors (Torabi, 2021; Mohadesi, 2021). It helps in extraction of large-scale text data and social computing as the process of extracting data from large text corpus is difficult (Avasthi et al., 2021; Wang et al., 2007).

Intelligence when used in social sectors or when dealing with people in social settings is called social intelligence. This kind of intelligence is required by each group of people and especially middle-aged during post and pre retirement phases, because of excess social exclusion. Literature review indicates that people have positive attitude towards retirement for the first six months as they experience freedom from job pressure, time demands and work-related stress (Gall et al., 1997). However, slowly this freedom turns into stress and their positive attitude towards life changes. This might be due to various financial constraints and limited recreational activities like travel (Kim \& Moen, 2001). But again, after some time, people start enjoying their retirement. Once again positive attitudes start developing as these retired people accommodate to their financial constraints and focus on structured activities (Mutran et al., 1997). Studies have also revealed that strong self esteem and positive internal control enhances a person's adjustment towards transition to retirement (Reitzes \& Mutran, 2004). Social factors play an important role and a person with enhanced social skills generally delays retirement (De Wind et al., 2014).

Secondary data also reveals that social intelligence helps in success ageing (Soleimani et al., 2020). According to Bassuk et al., 1999, there is a relationship existing among societal support and cognitive utility between the older adults. He said that older adults who faces excess social exclusion has a risk of decreasing cognitive ability. Fratiglioni et al., 2000, found that a social network and increase social ties reduces the occurrence of dementia in older people. Yeh and Liu (2003), also found older adults with good social support had high traits of intelligence and cognitive ability. More, study of Ertel et al. (2008) found that older adults who are socially integrated has less loss of memory.

There is a relationship between socio-economic status, environment of home and social intelligence among different age groups and different genders (Hunt, 1928). Our social strata economically affect our social intelligence which in turn affects our health, whereas our better environment of home also enhances our social intelligence (Kaur \& Kalaramna, 2004).

Further when we are happy our social intelligence enhances according to Bukaiei (2016) whereas Chapin (1939), Stokes and Jackson (2014), found that many parameters of social intelligence were greatly affected by our process of adjustment. Rezaei and Jeddi (2020), also found that a person's adjustment ability and their satisfaction is greatly affected by his or her social intelligence. Researchers found a positive relation between socially or emotionally intelligent people and their subjective well being which may ultimately lead to effective optimization of retirement. (Gallagher \& Vella-Brodrick, 2008; Amorim \& França, 2019). Our physical and mental health is affected by our social intelligence hence middle-aged people and older adults in our society can enhance their health by improving social intelligence. Social intelligence also helps in reducing stress and enhancing life satisfaction (Rezaei \& Jeddi, 2020). Further, research has also shown that positive activities, meditation, yoga and mindfulness exercises have always enhanced social, cultural and emotional intelligence and various competencies in people of all ages. (Thomas, 2006; Schutte 
\& Malouff, 2011). Hence, life-style management must arrange social activities for the middle aged and older adults or give them training in yoga, meditation or activities related to mindfulness to promote a better quality of life in them. This would enhance their social intelligence and help in proper optimization of their retirement.

\section{Hypotheses}

H1 - There is no significant difference between middle aged adults, just retired and older adults in terms of patience.

$\mathrm{H} 2$ - There is no significant difference between middle aged adults, just retired and older adults in terms of Cooperativeness.

H3 - There is no significant difference between middle aged adults, just retired and older adults in terms of Confidence.

H4 - There is no significant difference between middle aged adults, just retired and older adults in terms of Sensitivity.

H5 - There is no significant difference between middle aged adults, just retired and older adults in terms of Recognition of Social Environment.

H6 - There is no significant difference between middle aged adults, just retired and older adults in terms of Tactfulness.

H7 - There is no significant difference between middle aged adults, just retired and older adults in terms of Sense of Humour.

H8 - There is no significant difference between middle aged adults, just retired and older adults in terms of Memory.

\section{Methodology}

In this research the technique of sampling which was used is Purposive Sampling. In this the researchers choose the sample on their own judgment. The sample was the true representation of the population. In the present study certain factors like age, area and community, etc., are kept constant.

\section{Sample Characteristics}

1. The sample size was 252 (84 each from middle aged, just retired and older adults); all of them we're residing in planned housing.

2. The sample comprised of males only.

3. The age range of the subjects was 55-70 years (middle aged was from 55 to 60 years; just retired was from 61 to 64 years and older adults were from 65 to 70 years).

4. The samples were taken from Delhi/NCR.

5. The samples were living with at least one member of family.

6. The samples belonged to Hindu community. 


\section{Technique of Study}

The technique used in the present study was general administration of the Questionnaire method. The type of questionnaire used in the present study were closed and structured ones. The closed form of questionnaire is used, as the main objective is to obtain categorized data.

Further in this study interview method was also used for data collection. The prime aim of interview was to see whether the people in their transition phases are effectively utilizing their condition for proper optimization of retirement. The interviewer focused on the following parameters for assessing whether the subject is making an effective use of their retirement:

Financial management

$>$ Relationship with spouse

$>$ Active and Productive Ageing

$>$ Frequency of Travel

$>$ Health Management (Physical and Mental)

$>$ Frequency of Social Gatherings

$>$ Involvement in Household chores

\section{Description of the Tool Used}

The tool used for collection of data in this study was.

Scale of Social Intelligence developed by Dr.N.K.Chadha and Ms Usha Ganesan, (Chadha \& Ganesan, 1986).

The Social Intelligence Scale was developed as a result of experiments with various dimensions involved in social intelligence, carried out by experts in the field of behavioural science. The various dimensions that have been covered are:-Patience, Cooperativeness, Tactful behavior, Sense of Humour, Confidence level, Sensitivity, Recognition of Social Environment, and Memory.

The Layout for the scale was as discussed.

The number of dimensions in the scale was eight as discussed below in Fig. 1.

Fig. 1 Dimensions of Social Intelligence

\begin{tabular}{|l|l|l|}
\hline & Dimensions & Number of Items Retained \\
\hline 1. & Patience & 8 \\
\hline 2. & Cooperativeness & 11 \\
\hline 3. & Confidence & 8 \\
\hline 4. & Sensitivity & 9 \\
\hline 5. & Recognition of Social Environment, & 3 \\
\hline 6. & Tactfulness & 7 \\
\hline 7. & Sense of Humour & 8 \\
\hline 8. & Memory & 12 \\
\hline & TOTAL & 66 \\
\hline
\end{tabular}




\section{The Test Scoring}

The scores given were 3,2,1,0 based on the response chosen by the subject. The total score of each aspect is then graded in percentile and is then given a qualitative description.

\section{Reliability}

In this test, reliability co-efficient were found by retest and techniques of split half reliability. For this a sample was taken which consist of 50 male. The co-efficient obtained was 0.91 . The present scale has validity co-efficient of 0.71 .

\section{Results}

Hypotheses were that, "There is no significant difference between middle aged adults, retired and older adults in different parameters of Social Intelligence". To test this hypothesis the descriptive analysis was done. It was observed through descriptive analysis that older adults had less social intelligence than just retired and middle-aged adults as shown in Table 2, Figs. 2 and 3. Thus, the hypothesis was rejected. But in case of 'sensitivity' and 'recognition of social environment', the hypothesis was accepted as shown in Table 1. Results from the interview taken revealed that middle-aged and just retired people were able to optimize their situation of retirement more effectively than the elderly people.

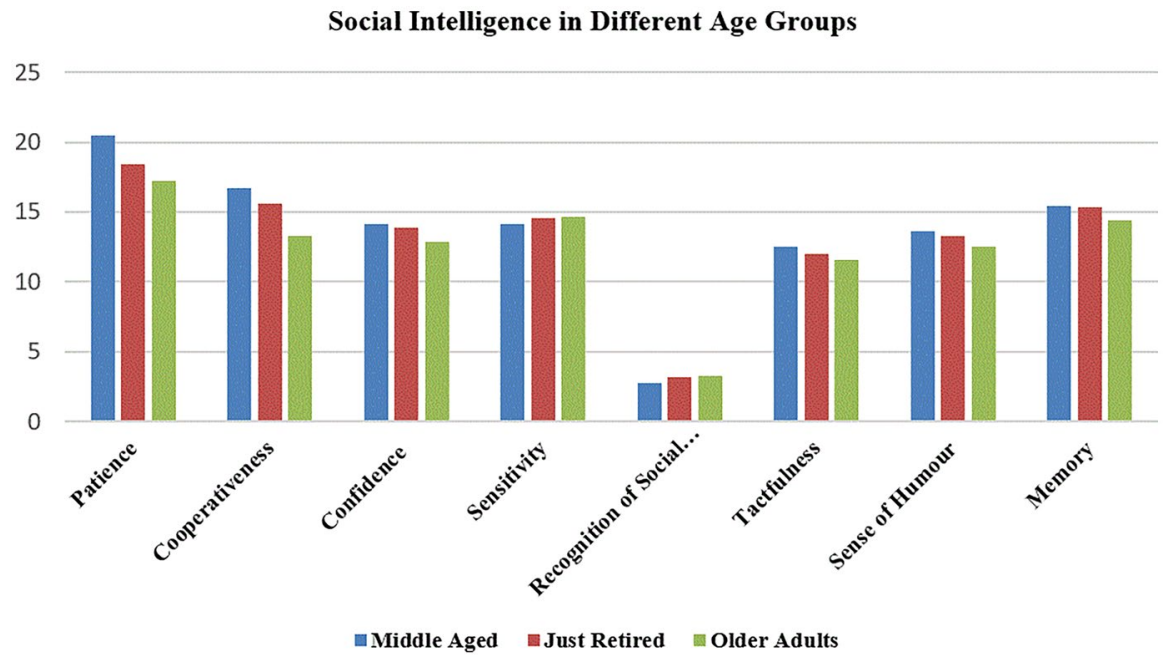

Fig. 2 Bar Graph showing the results of Table 2 


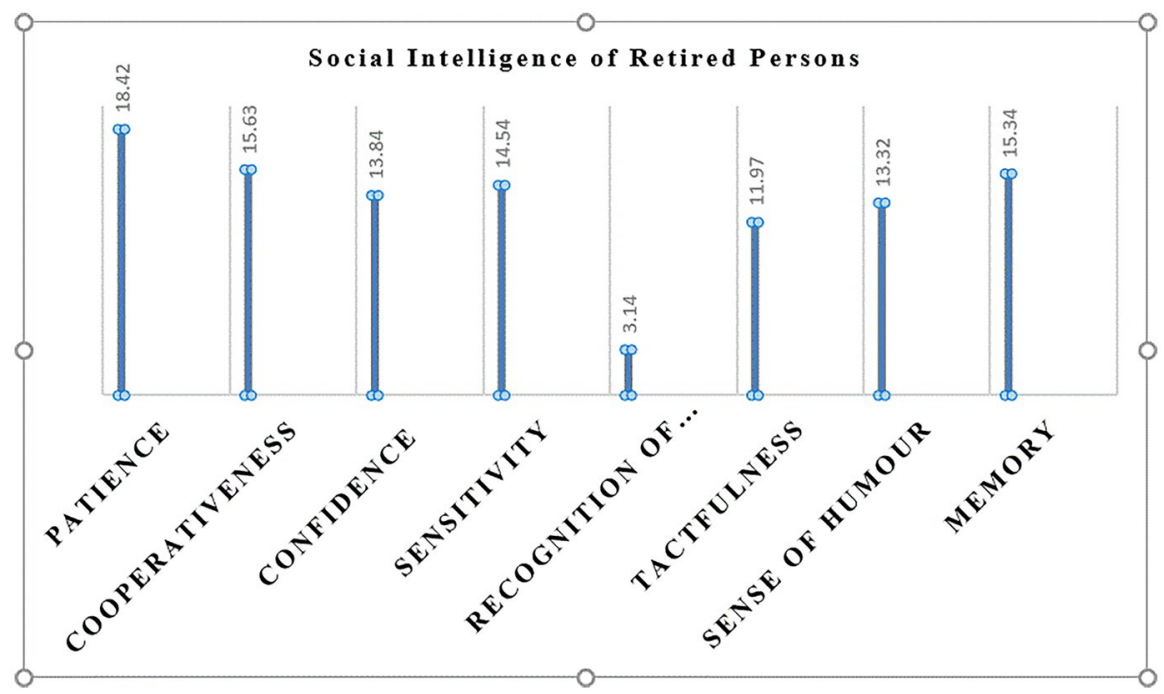

Fig. 3 Bar Graph showing the results of Retired persons

\section{Conclusion}

In the present investigation social intelligence of persons of different age groups were studied during their pre and post retirement transition phases. It was found from the obtained results that older adults, retired and middle aged differed significantly in most of the measures of social intelligence. (Ref. Table 2 and Fig. 2). Further from the interviews conducted it was found that middle aged and just retired were capable of effective optimization of their retirement. They had enhanced social intelligence and were physically and mentally fit to enjoy and utilized their time and skills post retirement. The results of the interview also indicated that middle aged people had effectively used their situation during the time of retirement. Middle aged people who were going to retire soon had proper planning and no financial constraints as per the interview taken. However, the Just Retired people had more finances than the older adults. The middle aged and just retired were with their

Table 1 Hypotheses

\begin{tabular}{ll}
\hline Hypotheses & Rejected/ Accepted \\
\hline H1 - & Rejected \\
H2 - & Rejected \\
H3 - & Rejected \\
H4- & Accepted \\
H5 - & Accepted \\
H6- & Rejected \\
H7 - & Rejected \\
H8 - & Rejected \\
\hline
\end{tabular}


Table 2 Descriptive Analysis Based on Age

\begin{tabular}{lll}
\hline Dimensions & Group & Mean \\
\hline Patience & Middle Aged & 20.51 \\
& Just Retired & 18.42 \\
Older Adults & 17.22 \\
Cooperativeness & Middle Aged & 16.67 \\
& Just Retired & 15.63 \\
Confidence & Older Adults & 13.29 \\
& Middle Aged & 14.17 \\
Sensitivity & Just Retired & 13.84 \\
& Older Adults & 12.84 \\
Recognition of Social Environ- & Middle Aged & 14.10 \\
ment & Middle Aged & 14.54 \\
& Just Retired & 14.66 \\
Tactfulness & Older Adults & 2.71 \\
& Older Adults & 3.14 \\
Sense of Humour & Middle Aged & 3.23 \\
& Just Retired & 12.50 \\
Memory & Older Adults & 11.97 \\
& Middle Aged & 11.53 \\
& Just Retired & 13.65 \\
& Older Adults & 13.32 \\
& Middle Aged & 12.55 \\
& Just Retired & 15.42 \\
& Older Adults & 15.34 \\
& & 14.42 \\
\hline
\end{tabular}

spouse and were effectively managing their time and health. They were involved in household chores and actively took part in society during any celebrations. However, the older adults were less productive and active. They also had health problems which made them immobile in travelling and taking part in social activities.

\section{Discussion}

Social Intelligence is a buzz word in today's era but it has an important role to play in different age groups. Social Intelligence also has a pivotal role to play during the phases of retirement. In the current study, analysis of social intelligence was done on people during their retirement phases to see whether this buzz word play any significant role in their adjustment process. The results showed a significant difference in all the parameters of social intelligence. In the area of patience, the three groups differed significantly. Older adults had less patience compared to middle aged and just retired. This may be because when these elderlies have to face more hardships, they fail to maintain their calmness. They may become irritated as they may have not planned properly for their retirement which accompanies many issues (Mutran et al., 1997). Financial constraints and limited recreation activities due to retirement or immobility due to pandemic condition can also 
be the cause (Kim \& Moen, 2001). In other words, it may be said that they lose their patience. However, middle aged adults may have a better ability to tolerate and deal any kind of stressful situations because of their low age, financial conditions and better health. The just retired persons have better scores than older adults. This might be due to their honeymoon stage or positive attitudes towards life as they experience freedom from job stress (Gall et al., 1997; Atchley, 1976). Further, from the conducted interview it was found that these middle-aged people had done proper optimization of their retirement. This may be due to high social intelligence, mental well being or good financial situation.

Further in the survey, middle aged in their pre retirement phase were found more cooperative than the just retired and older adults. This might be because the latter might not get along well with others due to their own health, social and psychological issues. They may be in the stage of termination due to novel corona virus (Atchley, 1976). When people are in their post retirement phase, generally their needs are not taken care of, and they have to try hard to fulfill them. They might have a social anxiety or difficultly to ease in the society because of their age (Furnham \& Pendleton, 1983). Often, they are not given proper recognition. For this they might have a difficulty to adjust with their surroundings, which in turn hampers the development of their social intelligence. This result is in line with Chapin (1939); Stokes and Jackson (2014); Jyoti and Kour (2017) who found that adjustment process and social intelligence are correlated.

A significant difference in the level of confidence was also seen in the three groups. Middle Aged are found more confident than the just retired and older adults. This again might be due to the better adjustment ability or social- emotional intelligence of the former.

However, middle aged were found to be less sensitive than older adults. This may be because of the neglected older adults which makes them suffer from loneliness, physical and psychological health problems, resulting in severe reparation of their emotions, and making them more sensitive (Risher et al., 2010) Moreover the people in their pre and post retirement phases are more happy and joyful due to lessening of job stress and time demands. (Gall et al., 1997).

Further, older adults were able to perceive better the events taking place in their surroundings. However, middle aged and just retired people perceived the environment in a less good manner than the older adults. This might be because the latter is more sensitive or has social maturity like people living in slums or living in detrimental conditions with poor health (Ajjampur et al., 2011). Another attribute of social intelligence, tactfulness is seen more in middle aged than the just retired and older adults. Former may have a better ability to deal situations tactfully than the latter due to their less age.

Generally, in transition to retirement the people first anticipate and then become acclimatize to their new life. (Reitzes et al., 1996). The process of retirement depends on many social and psychological issues, especially during the time of pandemic. Many aspects like status, finance, condition of health and education persuade the progression of retirement (Kim \& Moen, 2001). Many researches have also suggested that income and health are strongly associated 
with contentment, morale and well being of a person during pre and post retirement phases. ((Richardson \& Kilty, 1991).

Detrimental conditions of older adults make them face hardships of life. They have to facade the darker side of life all alone, specially without a spouse. Hence their capacity to feel and cause amusement is destroyed. On the other hand, middle aged and retired are still with their partners; hence they can take things easily and enjoy humour.

A significant difference has also been found regarding memory. This may be due to the social environment of the older adults which affects the memory (Ertel et al., 2008).

To sum up we can say that middle aged has higher social intelligence than the just retired and older adults. Effective optimization of retirement was properly done by these middle-aged persons and just retired. This may be due to many factors like intelligence, age of a person, his home environment or other social issues. (Boone et al., 1993; Kaur \& Kalaramna, 2004; Yeh \& Liu, 2003; Chand, 2018). On the basis of review of literature, we can also say that an older adults have low social intelligence and is unable to optimize his retirement effectively. Factors like poor physical and mental health or pandemic conditions like less travel or lonely environment increases the difficulty of persons during their middle-ages to deal with their retirement issues effectively.

\section{Limitations and Future Scope}

The present research only did descriptive analysis of mean to find social intelligence of different aged groups. Future study can be done for designing possible interventions or training program in enhancing social cognition and health of just retired people and older adults which may in turn improve their social intelligence and help in effectual optimization of retirement. Also, the present research only focused on male populations of Delhi- NCR hence further researches on females or older adults who are widows may be taken up to see the effect of loneliness and feminization on transition to retirement and ageing. Additionally, proper rehabilitation strategies may be planned for the needy and destitute older adults as these aged populations are facing many challenges in the developing countries (Chand, 2018). Study related to their pension, health care facilities and changing family dynamics can also be taken up to help the policy makers in framing policies related to aged.

\section{Declarations}

Conflict of Interest The authors declare that there is no conflict of interest.

Informed Consent None.

Ethical Treatment of Experimental Subjects (Animals and Humans) No experimental treatment was conducted on either human or animal subjects in this study. 


\section{References}

Ajjampur, S. S. R., Koshy, B., Venkataramani, M., Sarkar, R., Joseph, A. A., Jacob, K. S., \& Kang, G. (2011). Effect of cryptosporidial and giardial diarrhoea on social maturity, intelligence and physical growth in children in a semi-urban slum in south India. Annals of Tropical Paediatrics, 31(3), 205-212. https://doi.org/10.1179/1465328111Y.0000000003

Amorim, S. M., \& França, L. H. D. F. P. (2019). Retirement well-being: A systematic review of the literature. Trends in Psychology, 27, 155-172. https://doi.org/10.9788/TP2019.1-12

Atchley, R. C. (1976). The sociology of retirement. John Wiley.

Avasthi S., Chauhan R., \& Acharjya D. P. (2021). Techniques, Applications, and Issues in Mining LargeScale Text Databases. In: Goar V., Kuri M., Kumar R., Senjyu T. (eds) Advances in Information Communication Technology and Computing. Lecture Notes in Networks and Systems, vol 135. Springer, Singapore. https://doi.org/10.1007/978-981-15-5421-6_39

Bassuk, S. S., Glass, T. A., \& Berkman, L. F. (1999). Social engagement and incident cognitive decline in community - dwelling elderly persons. Annals of Internal Medicine, 131, 165-173. https://doi.org/ 10.7326/0003-4819-131-3-199908030-00002

Bonesso, S., Bruni, E., \& Gerli, F. (2020). Emotional and social intelligence competencies in the digital era. In Behavioral competencies of digital professionals (pp. 41-62). Palgrave Pivot, Cham. https:// doi.org/10.1007/978-3-030-33578-6_3

Boone, K. B., Ghaffarian, S., Lesser, I. M., Hill-Gutierrez, E., \& G. Berman, N. (1993). Wisconsin Card Sorting Test performance in healthy, older adults: Relationship to age, sex, education, and IQ. Journal of Clinical Psychology, 49(1), 54-60.

Boyatzis R.E., Gaskin J., \& Wei, H. (2015). Emotional and Social Intelligence and Behavior. In: Goldstein S., Princiotta D., Naglieri J. (eds) Handbook of Intelligence. Springer, New York, NY. https://doi.org/10. 1007/978-1-4939-1562-0_17

Bukaiei, N. A. (2016). Social Intelligence as a Predictor of the Feeling of Happiness among Students of the Faculty of Educational Sciences and Arts/UNRWA. Journal of Educational and Psychological Studies [JEPS], 10(1), 201-221. https://doi.org/10.24200/jeps.vol10iss1pp201-221

Chadha, N. K., \& Ganesan, U. (1986). Publication manual for social intelligence scale. National Psychological Corporation, 4, 230.

Chand, M. (2018). Aging in South Asia: Challenges and opportunities. South Asian Journal of Business Studies. https://doi.org/10.1108/SAJBS-09-2017-0103

Chapin, F. S. (1939). Social participation and social intelligence. American Sociological Review, 4(2), 157-166. https://doi.org/10.2307/2084201

Crowne, K. A. (2009). The relationships among social intelligence, emotional intelligence and cultural intelligence. Organization Management Journal, 6(3), 148-163. https://doi.org/10.1057/omj.2009. 20

De Wind, A., Geuskens, G. A., Ybema, J. F., Blatter, B. M., Burdorf, A., Bongers, P. M., \& Van der Beek, A. J. (2014). Health, job characteristics, skills, and social and financial factors in relation to early retirement-results from a longitudinal study in the Netherlands. Scandinavian journal of work, environment \& health, 186-194. https://doi.org/10.5271/sjweh.3393

Ertel, K. A., Glymour, M. M., \& Berkman, L. F. (2008). Effects of social integration on preserving memory function in a nationally representative US elderly population. American Journal of Public Health, 98(7), 1215-1220. https://doi.org/10.2105/AJPH.2007.113654

Fratiglioni, L., Wang, H. X., Ericsson, K., Maytan, M., \& Winblad, B. (2000). Influence of social network on occurrence of dementia: A community-based longitudinal study. Lancet, 355, 1315-1319. https://doi.org/10.1016/s0140-6736(00)02113-9

Furnham, A., \& Pendleton, D. (1983). The assessment of social skills deficits in the elderly. The International Journal of Aging and Human Development, 17(1), 29-38. https://doi.org/10.2190/ 9Y98-6CQB-PYTY-U668

Gall, T. L., Evans, D. R., \& Howard, J. (1997). The retirement adjustment process: Changes in the wellbeing of male retirees across time. The Journals of Gerontology Series b: Psychological Sciences and Social Sciences, 52B(3), P110-P117. https://doi.org/10.1093/geronb/52B.3.P110

Gallagher, E. N., \& Vella-Brodrick, D. A. (2008). Social support and emotional intelligence as predictors of subjective well-being. Personality and Individual Differences, 44(7), 1551-1561. https://doi.org/ 10.1016/j.paid.2008.01.011 
Garfein, A. J., \& Herzog, A. R. (1995). Robust aging among the young-old, old-old, and oldest-old. The Journals of Gerontology Series B: Psychological Sciences and Social Sciences, 50(2), S77S87. https://doi.org/10.1093/geronb/50B.2.S77

Green, R. F. (1969). Age-intelligence relationship between ages sixteen and sixty-four: A rising trend. Developmental Psychology, 1(5), 618-627. https://doi.org/10.1037/h0027879

Havighurst, R. J. (1972). Developmental Tasks and Education (3rd ed.).

Hunt, T. (1928). The measurement of social intelligence. Journal of Applied Psychology, 12(3), 317. https://doi.org/10.1037/h0075832

Hurlock, E. B. (1980). Instructor's Manual to Accompany" Developmental Psychology, a Life-span Approach.". McGraw-Hill.

Insa-Cabrera, J., Benacloch-Ayuso, J. L., \& Hernández-Orallo, J. (2012). On Measuring Social Intelligence: Experiments on Competition and Cooperation. In: Bach J., Goertzel B., Iklé M. (eds) Artificial General Intelligence. AGI 2012. Lecture Notes in Computer Science, vol 7716. Springer, Berlin, Heidelberg. https://doi.org/10.1007/978-3-642-35506-6_14

Jyoti, J., \& Kour, S. (2017). Factors affecting cultural intelligence and its impact on job performance: Role of cross-cultural adjustment, experience and perceived social support. Personnel Review, 46(4), 767-791. https://doi.org/10.1108/PR-12-2015-0313

Kaur H; Kalaramna. (2004). A Study of interrelationship between home environment, social intelligence and socio-economic status among males and females. Journal of Human Ecology, 16(2), 137-140. https://doi.org/10.1080/09709274.2004.11905728

Khilmiyah, A., \& Wiyono, G. (2021). Emotional and social intelligence assessment model for student character reinforcement. International Journal of Educational Management., 35(4), 789-802. https://doi.org/10.1108/IJEM-02-2020-0046

Kihlstrom, J. F., \& Cantor, N. (2000). Social intelligence. In R. J. Sternberg (Ed.), Handbook of intelligence (pp. 359-379). Cambridge University Press. https://doi.org/10.1017/CBO9780511807947. 017

Kim, J. E., \& Moen, P. (2001). Moving into retirement: Preparations and transitions in late midlife. In M. E. Lachman (Ed.), Handbook of midlife development (pp. 487-527). John Wiley and Sons.

Kircaburun, K., Demetrovics, Z., Griffiths, M. D., Király, O., Kun, B., \& Tosuntaş, ŞB. (2020). Trait emotional intelligence and internet gaming disorder among gamers: The mediating role of online gaming motives and moderating role of age groups. International Journal of Mental Health and Addiction, 18(5), 1446-1457. https://doi.org/10.1007/s11469-019-00179-x

Mohadesi, E. (2021). An examination of the relationship between social intelligence and organisational commitment among the school managers of Kashmar and Khalilabad. Global Journal of Guidance and Counseling in Schools: Current Perspectives, 11(2), 98-109. https://doi.org/10.18844/gjgc. v11i2.5705

Mutran, E. J., Reitzes, D. C., \& Fernandez, M. E. (1997). Factors that influence attitudes toward retirement. Research on Aging, 19, 251-273. https://doi.org/10.1177/0164027597193001

O'Sullivan, M. (1965). Behavioral (social) intelligence: A factor analysis. University of Southern California.

Pamuk, Ç. A. (2020). Memory, Identity and Old Age: The Sense of an Ending as the Story of Ageing. Cankaya University Journal of Humanities and Social Sciences, 14(2), 229-239. https://doi. org/10.47777/cankujhss.848905

Papaioannou, A. G., Schinke, R. J., Chang, Y. K., Kim, Y. H., \& Duda, J. L. (2020). Physical activity, health and well-being in an imposed social distanced world. https://doi.org/10.1080/1612197X. 2020.1773195

Picchio, M., \& Van Ours, J. C. (2020). Mental health effects of retirement. De Economist, 168(3), 419452. https://doi.org/10.1007/s10645-020-09369-8

Reitzes, D. C., \& Mutran, E. J. (2004). The transition to retirement: Stages and factors that influence retirement adjustment. The International Journal of Aging and Human Development, 59(1), 63-84.

Reitzes, D. C., Mutran, E. J., \& Fernandez, M. E. (1996). Pre-retirement influences on post-retirement self-esteem. Journal of Gerontology, 51B, S242-S249. https://doi.org/10.1093/geronb/51B.5.S242

Rezaei, A., \& Jeddi, E. M. (2020). Relationship between wisdom, perceived control of internal states, perceived stress, social intelligence, information processing styles and life satisfaction among college students. Current Psychology, 39(3), 927-933. https://doi.org/10.1007/s12144-018-9804-z

Richardson, V., \& Kilty, K. M. (1991). Adjustment to retirement: Continuity vs. discontinuity. International Journal of Aging and Human Development, 33, 151-169. https://doi.org/10.2190/ 6RPT-U8GN-VUCV-P0TU 
Risher, J. F., Todd, G. D., Meyer, D., \& Zunker, C. L. (2010). The elderly as a sensitive population in environmental exposures: Making the case. Reviews of Environmental Contamination and Toxicology, 207, 95-157. https://doi.org/10.1007/978-1-4419-6406-9_2

Santini, Z. I., Jose, P. E., Koyanagi, A., Meilstrup, C., Nielsen, L., Madsen, K. R., \& Koushede, V. (2020). Formal social participation protects physical health through enhanced mental health: A longitudinal mediation analysis using three consecutive waves of the Survey of Health, Ageing and Retirement in Europe (SHARE). Social Science \& Medicine, 251, 112906. https://doi.org/10.1016/j.socscimed. 2020.112906

Schutte, N. S., \& Malouff, J. M. (2011). Emotional intelligence mediates the relationship between mindfulness and subjective well-being. Personality and Individual Differences, 50(7), 1116-1119. https://doi.org/10.1016/j.paid.2011.01.037

Sneegas, J. J. (1986). Components of life satisfaction in middle and later life adults: Perceived social competence, leisure participation, and leisure satisfaction. Journal of Leisure Research, 18(4), 248258. https://doi.org/10.1080/00222216.1986.11969663

Soleimani, M. A., Mohammadi, F., Mafi, M., \& Zakani, A. (2020). The predictive role of social intelligence in successful aging in the elderly. Social Health and Behavior, 3(4), 166. https://doi.org/10. 4103/SHB.SHB_44_20

Stokes, L. D., \& Jackson, Y. (2014). Community violence and psychological adjustment in youth: Role of emotional-social intelligence. Journal of Child \& Adolescent Trauma, 7(1), 17-26. https://doi.org/ 10.1007/s40653-014-0006-Z

Stuart-Hamilton, I., Nayak, L., \& Priest, L. (2006). Intelligence, belief in the paranormal, knowledge of probability and aging. Educational Gerontology, 32(3), 173-184. https://doi.org/10.1080/ 03601270500476847

Thakur, R., Sharma, S., \& Pathania, R. (2013). Social intelligence of adolescents: A study of Himachal Pradesh. studies on Home and community science, 7(3), 161-166. https://doi.org/10. 1080/09737189.2013.11885408

Thomas, D. C. (2006). Domain and development of cultural intelligence: The importance of mindfulness. Group \& Organization Management, 31(1), 78-99. https://doi.org/10.1177/1059601105275266

Torabi, Z. (2021). Investigating the relationship between social intelligence of marketing managers on organizational learning of staff of insurance centers in Isfahan. Journal of Engineering in Industrial Research, 2(1), 36-43. https://doi.org/10.22034/JEIRES.2021.269830.1024

Wang, F. Y., Carley, K. M., Zeng, D., \& Mao, W. (2007). Social computing: From social informatics to social intelligence. IEEE Intelligent Systems, 22(2), 79-83. https://doi.org/10.1109/MIS.2007.41

Wechsler, D. (1944). The measurement of adult intelligence (3rd ed.). Williams \& Wilkins Co. https:// doi.org/10.1037/11329-000

Xie, L., Shen, Y., Wu, Y., \& Yang, H. (2021). The impact of retirement on mental health. The International Journal of Health Planning and Management. https://doi.org/10.1002/hpm.3240

Yeh, S. C. J., \& Liu, Y. Y. (2003). Influence of social support on cognitive function in the elderly. BMC Health Services Research, 3, 9. https://doi.org/10.1186/1472-6963-3-9

Yeh, Z. T. (2013). Role of theory of mind and executive function in explaining social intelligence: A structural equation modeling approach. Aging \& Mental Health, 17(5), 527-534. https://doi.org/10. $1080 / 13607863.2012 .758235$

Publisher's Note Springer Nature remains neutral with regard to jurisdictional claims in published maps and institutional affiliations.

Ms. Tanushree Sanwal is a research scholar in Amity University, Noida. She has 15 years of teaching and research experience. Her area of expertise is Human Development and Organizational Behavior. She has published several papers in national and international journals.

Dr. Puja Sareen is an Associate Professor in Amity University, Noida. She has 20 years of teaching and industry experience. Her area of expertise is Human Resource Management and Training. She has published several papers in national and international journals. 